\title{
PEMBERDAYAAN IBU RUMAH TANGGA DALAM PEMANFAATAN PEKARANGAN MELALU KELOMPOK WANITA TANI (KWT) SANGGAR REZEKI
}

\author{
Sri Mandayani ${ }^{1 *}$, Rosdiana ${ }^{2}$ \\ ${ }^{1}$ Program Studi Pendidikan Nonformal, Universitas Negeri Medan \\ ${ }^{2}$ Program Studi Pendidikan Masyarakat, Universitas Negeri Medan \\ * Korespondensi Penulis. Email: srimandayani@gmail.com
}

\begin{abstract}
Abstrak
Masalah dalam penelitian ini adalah kurang berdayanya ibu rumah tangga di desa karang anyar, belum dimanfaatankanya secara optimal pekarangan di desa karang anyar, dan kemiskinan serta pemenuhan kebutuhan pangan keluarga. Metode yang digunakan dalam penelitian ini adalah deskriptif kuantitatif, informan dalam penelitian ini adalah anggota kelompok sebagai informan kunci. Populasi dan sample dalam penelitian ini adalah 30 ibu rumah tangga anggota kelompok wanita tani. Teknik penentuan sample dalam penelitian ini adalah teknik Nonprobality Sampling. Teknik pengumpulan data yang dgunakan adalah angket dan dokumentasi, data yang dikumpulkan diolah dan dianalisis dengan menggunakan rumus presentase: $\mathrm{P}=\frac{\mathrm{F}}{\mathrm{N}} \times 100 \%$. Hasil penelitian ini menunjukan beberapa tahap upaya pemberdayaan yang dilakukan dalam kegiatan pemanfaatan pekarangan oleh kelompok wanita tani yaitu perencanaan program kegiatan yang dilakukan oleh PPL kepada anggota kelompok sangat baik, pelaksanaan program kegiatan serta evaluasi program kegiatan pemberdayaan sangat baik.
\end{abstract}

Kata Kunci: Pemberdayaan, Ibu Rumah Tangga, Kelompok Tani

\begin{abstract}
The problem in this study is the lack of empowerment of housewives in the village of Karang Anyar, it has not been utilized optimally on the grounds in the newer coral villages, and poverty and fulfillment of family food needs. The method used in this research is descriptive quantitative, the informants in this study were group members as key informants. The population and sample in this study were 30 housewives members of the female farmer group. The sample determination technique in this study is the Nonprobality Sampling technique. Data collection techniques used are questionnaires and documentation, collected data is processed and analyzed using the percentage formula: $P=F / N \times 100 \%$. The results of this study indicate several stages of empowerment efforts carried out in yard utilization activities by women farmer groups, namely the program planning of activities carried out by PPL to group members is very good, the implementation of program activities and evaluation of empowerment activities programs is very good.
\end{abstract}

Keywords: Empowerment, Housewives, Farmers Group 


\section{PENDAHULUAN}

Pemberdayaan adalah sebuah konsep pembangunan ekonomi yang merangkum nilai-nilai sosial. Pemberdayaan merupakan upaya pemberian kesempatan dan memfasilitasi kelompok miskin agar mereka memiliki aksebilitas terhadap sumberdaya yang berupa: modal, teknologi, informasi, dan jaminan pemasaran, agar mereka mampu memajukan dan mengembangkan usahanya, sehingga memperoleh perbaikan pendapatan serta perluasan kesempatan kerja demi perbaikan kehidupan dan kesejahteraan.

Upaya pemberdayaan masyarakat semakin menjadi kebutuhan, dalam setiap upaya pembangunan dalam rangka peningkatan taraf hidupnya dan merupakan usaha untuk membentuk kemandirian dalam diri masyarakat desa. Pada tahap selanjutnya segala permasalahan yang ada di sekitar masyarakat desa dapat diselesaikan dan diatasi oleh masyarakat desa itu sendiri. Salah satu yang menjadi masalah pada masyarakat

desayaitu kemiskinan dan pemenuhan kebutuhan pangan dalam rumah tangga.

Kegiatan awal yang dilakukan Kelompok Wanita Tani dalam proses pengolahan lahan pekarangan adalah melakukan pengelolaan lahan pekarangan yang telah lama tidak digunakan dengan tumbuhnya rumput-rumput liar disekitar pekarangan, agar dapat ditanami dengan tanaman-tanaman yang bermanfaat bagi keluarga dan masyarakat serta ibu-ibu rumah tangga juga dapat melakukan kegiatan di luar rumah dengan bercocok tanam di pekarangan rumah.Dari hasil identifikasi tanaman yang sesuai untuk ditanam dipekarangan rumah oleh ibu-ibu rumah tangga ditemukan beberapa jenis sayuran dan tanaman obat keluarga (TOGA) seperti kunyit, jahe,bawang, sawi, cabe, kangkung, bayam, dan tumbuhan lainya yang dapat di panen lebih cepat.

Berdasarkan uraian diatas maka penulis merasa tertarik untuk meneliti dan menemukan jawaban para ibu rumah tangga di kelompok wanita tani yang sedang menjalani pembinaan melalui pemanfaatan pekarangan. Apakah kegiatan pembinaan pemanfaatan pekarangan dapat memberdayakan ibu rumha tangga dan memberi semangat dan motivasi dalam menjalani pembinaan sehingga memperoleh kehidupan yang lebih baik untuk keluarga.

\section{METODE}

Dalam penelitian ini peneliti menggunakan jenis penelitian deskriptif kuantiitatif. Metode deskriptif adalah suatu metode dalam meneliti status sekelompok manusia, tujuan penelitian ini yaitu untuk membuat deskripsi, gambaran secara sistematis, faktual dan akurat. Dalam penelitian ini yang menjadi populasi peneliti adalah seluruh jumlah anggota dari Kelompok Wanita Tani (KWT) Sanggar Rezeki yang berjumlah 30 orang. Sampel yang digunakan adalah sampling jenuh yaitu sesuai dengan yang diungkapkan Sugiyono (2013) yaitu berjumlah 30 orang anggota kelompok wanita tani yang memanfaatkan lahan pekarangannya.

\section{HASIL DAN PEMBAHASAN}

Berawal dari kesulitan untuk memenuhi kebutuhan pokok sehari-hari para petani kesulitan mencari lapangan kerja yang ada didesa sebagai buruh tani, itu pun harus berpindah-pindah dari satu desa ke desa lain yang hanya berjalan selama dua bulan, selebihnya mencari upah dengan menjadi buruh bangunan. sedangkan kaum ibu-ibu hanya mengambil upah tandur, dengan tuntutan kebutuhan yang terus mendesak akan kebutuhan pangan sehari-hari.

Pada Tahun 2013 PPL Desa Karang Anyar mulai mencari terbosan keluar mencari bantuan ke Dinas terkait seperti BPTPP Provinsi, BKKP Kabupaten Deli Serdang dan Dinas Pertanian Kabupaten Deli Serdang, dalam tahun yang sama kelompok wanita tani mendapat bantuan satu unit Kawasan Rumah Pangan Lestari (KRPL) lengkap dengan benih,tanah subur,kompos, plibag, 1 unut kebun bibit dari BPTP Provinsi. Kelompok Wanita Tani yang tergabung dalam gerakan PKK bersatu 
padu membangun dan mengajak seluruh ibu-ibu untuk memanfaatkan lahan pekarangan, benihpun mulai disemai dengan bergotong royong benih yang siap untuk ditanam dibagikan pada setiap anggota kelompok dan masyarakat. Dengan berjalannya waktu sayuran yang sudah tumbuh subur dan dapat dipanen, hasilnya dijual ke pasar atau desa-desa tetangga dan uangnya dikumpulkan untuk dibelikan ke bibit lagi.. Sebagai contoh, dapat dilihat Tabel 1.

Tabel 1. AnalisiData Hasil Penelitian

\begin{tabular}{|c|c|c|c|}
\hline No & $\begin{array}{l}\text { Pemanfaatan } \\
\text { Lahan } \\
\text { Pekarangan } \\
\text { Melalui Kelompok } \\
\text { Wanita Tani } \\
\text { (KWT) }\end{array}$ & $\%$ & Keterangan \\
\hline 1 & $\begin{array}{l}\text { Perencanaan } \\
\text { Program }\end{array}$ & 81.8 & $\begin{array}{l}\text { Sangat } \\
\text { Baik }\end{array}$ \\
\hline 2 & $\begin{array}{l}\text { Pelaksanaan } \\
\text { Program }\end{array}$ & 75,7 & $\begin{array}{l}\text { Sangat } \\
\text { Baik }\end{array}$ \\
\hline 3 & $\begin{array}{l}\text { Evaluasi } \\
\text { Program }\end{array}$ & 77,7 & $\begin{array}{l}\text { Sangat } \\
\text { Baik }\end{array}$ \\
\hline & Jumlah & 7,84 & $\begin{array}{l}\text { Sangat } \\
\text { Baik }\end{array}$ \\
\hline
\end{tabular}

\section{SIMPULAN}

Berdasarkan hasil penelitian yang dilakukan, maka dapat disimpulkan bahwa upaya pemberdayaan ibu rumah tangga dalam pemanfaatan pekarangan Melalui Kelompok Wanita Tani (KWT) Sanggar Rezeki di Desa Karang Anyar sangat baik, dapat dilihat dari

1. Ibu Rumah Tangga telah memanfaatkan pekarangan di Desa Karang Anyar dengan baik

2. Proses pemanfaatan pekarangan untuk memberdayakan Ibu Rumah Tangga di Desa Karang Anyar berjalan dengan baik

3. Tingkat pemberdayaan oleh Dinas Pertanian untuk peningkatan kebutuhan pangan dan ekonomi keluarga juga berjalan dengan sangat baik

\section{DAFTAR PUSTAKA}

Alex S, 2014. Sayuran Dalam Pot Sayuran Konsumsi Tak Harus Beli. Yogyakarta: Pustaka Baru Perss.

Amanah, Siti \& Narni Farmayanti, 2014. Pemberdayaan Sosial Petani-Nelayan, Keunikan Agroekosistem, dan Daya Saing. Jakarta: Yayasan Pustaka Obor Indonesia.

Kaime,Edi, 2013,Kecamatan Beringin Dalam Angka 2013, Koordinator Statistik Kecamatan Beringin.

Fuad, Nurhayati,2014. Manajemen Pendidikan Berbasis masyarakat konsep dan strategi implikasi, Jakarta:rajawali pers.

Ginting, M. 2010. Eksplorasi Pemanfaatan Pekarangan secara Konseptual Sebagai Konsep"Program Gerakan Dinas Pertanian Kota Pematangsiantar".

Husaini \& Purnomo. 2009. Metodologi Penelitian Sosial Edisi Kedua. Jakarta: Bumi Aksara

Iskandar, 2009. Metode Penelitian Kualitatif (Aplikasi untuk Penelitian Pendidikan, Hukum, Ekonomi \& Manajemen, Sosial, Humaniora, Politik, Agama, dan Filsafat ), Jakarta: Gaung Persada.

Kristanti. 2012. Optimalisasi Pemanfaatan Pekarangan Menjadi Taman Yang Produktif. Uripsantosowordpress.com diakses tanggal 15 Maret 2015

Listiani, Dkk. 2002. Gender dan komunitas perempuan pedesaan, kondisi nyata yang terjadi dilapangan. Medan: Bitra Indonesia.

Manurung. 2012. Metodologi penelitian. Jakarta : KDT Halaman Moeka.

Mardikanto \& Soebiato, 2015. Pemberdayaan Masyarakat ( Dalam Perspektif Kebijakan Publik). Bandung. Alfabeta.

Page | 34

\author{
(1)
}


Journal of Millennial Community, 1 (1), March 2019

Sri Mandayani, Rosdiana

Sugiyoni. 2013. MetodePenelitian Pendidikan, Kuantitatif, Kualitatif Dan $R \& D$. Bandung: Alfabeta

Syafari, Agus, 2014. Kemiskinan dan Pemberdayaan Kelompok, Yogyakarta: Graha Ilmu.

Tukiran, dkk, 2007. Sumber Daya Manusia Tantangan Masa Depan. Yogyakarta: Pustaka Pelajar \& PSKK UGM.

Tim Pengajar, 2015. Pedoman Penulisan Skripsi .FIP Medan: UNIMED

Yuni \& Sri. 2003. Merajut perubahan, sebuah catatan harian perempuan dalam pengelolaan program pemberdayaan perempuan. Klaten: Persepsi.

2010. Undang-Undang Republik Indonesia No.20 Tahun 2003 tentang SISIDIKNAS \& Peraturan Pemerintah Republik Indonesia Tahun 2010 tentang Penyelenggaraan Pendidikan serta Wajib Belajar. Bandung: Citra Umbara.
Ashari dkk, Mei 2012,Potensi dan Orospek Pemanfaatan Lahan Pekarangan Untuk Mendukung Ketahanan Pangan,Pusat Sosial Ekonomi dan Kebijakan Pertanian,2012.

Ramansyah, Farid dkk,2015, Analisis Modal Sosial Anggota Kelompok Wnita Tani Dlama Program Model Kawasan Rumah Pangan Lestari(M-KRPL) di Desa Tualang Kecamatan Tualang Kabupaten Siak, Jom Faperta Vol 2 No 1 Februari 2015

Susilo, Bambang. 2015. Pemberdayaan Ekonomi Perempuan Tani Berbasis Kelembagaan, Muwarah.Vol.2, No.2, Desember 2010.

Yaningwati Fransiska,2015, Peberdayaan SDM Perempuan Pada Sektor Agribisnis,Jurnal Administrasi Bisnis Vol I, No.1,Juni 2007.

Werdhany, Wiendarti dan Gunawan,2012, Teknik Pengembangan Kawasan Rumah Pangan Lestari di DIY, Jurnal Ilmu-ilmu Pertanian,Volume 16,Nomor2,Desember 2012. 